JOURNAL of

CONTEMPORARY INDONESIAN

ART

Jurusan Seni Murni

FSR ISI Yogyakarta

ISSN: 2442-3394

E-ISSN: 2442-3637

\section{RELASI NARASI VISUAL DAN TEKS DALAM IKON TRANSFIGURASI PAROKI ST. DIONYSIOS YOGYAKARTA}

\author{
oleh: Alex Cristian Justisia Ginting, S.Ds. \\ Pascasarjana ISI Yogyakarta \\ Alchristaegin@gmail.com
}

\begin{abstract}
Abstrak
Seni lukis Byzantine adalah salah satu warisan kesenian dunia yang belum banyak dibahas oleh kalangan akademisi seni di Indonesia. Warisan seni lukis Byzantine sering disamakan dengan Ikonografi, yaitu gambar-gambar suci yang sampai hari ini masih dipertahankan fungsinya dalam gereja-gereja yang menggunakan ritus Byzantine (Gereja Orthodox dan Gereja Katolik Ritus Byzantine). Seni Byzantine dibagi tiga periode, yaitu awal, tengah, dan akhir, dimana pada periode TengahAkhir muncul ikon berjenis Menologion. Seni lukis Byzantine dikaji menggunakan Ikon Pesta Transfigurasi yang merupakan digitalisasi dari ikon aslinya yang berasal dari abad ke-16 untuk menjelaskan bentuk visual, struktur dan hubungannya dengan narasi. Kajian menemukan ada kesamaan antara visualisasi narasi ikon dengan struktur pesta Gerejawi yang memiliki tiga pola (Pra Pesta - Pesta - Pasca Pesta/Apodosis).
\end{abstract}

Kata kunci: Seni Rupa, Seni Gerejawi, Ikonografi, Byzantine. 


\section{A. Pendahuluan}

Seni dapat dimanfaatkan untuk menerangkan suatu ajaran atau pemahaman (Marianto, 2019, hal. 23). Seni dihayati oleh Gereja Orthodox, salah satunya dengan memanfaatkan gambar-gambar suci sebagai alat bantu dalam kehidupan kerohaniannya. Dalam bahasa Yunani disebut, gambar disebut sebagai عiko่v (ikon). Kata Ikon dalam dunia seni dikenal pula sebagai seni lukis yang khas dan penggunannya masih digunakan oleh oleh Gereja Orthodox dan Gereja Katolik. Dengan demikian, ikon berhubungan dengan kehidupan keagamaan dan ilmu ketuhanan atau teologi. Theodor Damian menjelaskan bahwa teologi ikon merepresentasikan salah satu ajaran mendasar iman Kristen Orthodox yang terhubung dengan masalahmasalah Kristologi (ilmu tentang pribadi Yesus Kristus). Ikon dipahami sebagai sebuah tanda kehadiran Ilahi dalam dunia serta berfungsi sebagai pengingat hubungan antara manusia dengan Tuhan. Sejak awal dari kehidupan Gereja Kristen (abad pertama), gambar telah digunakan sebagai representasi pemikiran inkarnasional dalam teologi Kristiani, yaitu pemikiran tentang Firman Allah yang menjelma menjadi manusia. Gambar juga dianggap menjadi pelengkap dari kitab injil sebagaimana keduanya membicarakan hal yang sama (McGuckin, 2010, hal. 330).

$$
\text { Philip Zymaris menjelaskan }
$$

(McGuckin, 2010, hal. 327) bahwa gaya seni rupa Kristiani pada awalnya sangat erat dengan gaya artistik dunia kuno/Antiquity. Gaya gambar Ikonografi berkembang dalam beberapa tahap yaitu Byzantine Awal (abad 4-8), Byzantine Tengah (827-1024), dan Byzantine Akhir (1204-1453). Peninggalan Byzantine Awal masih dapt kita lihat di kuburan bawah tanah (katakomba) dan sarkofagus dari periode Late Antiquity dan pada bangunan-bangunan peninggalan pemerintahan Konstantinus (abad 4) dan Justinian (abad 6). Masa Byzantine awal merepresentasikan dua tendensi sekaligus yaitu gaya Yunani/Hellenis yang cenderung naturalis dan dibumbui dengan pemikiran matiraga/askese Kristiani. Juga terlihat gaya Oriental yang cenderung lebih terang dan cerah dan lebih umum muncul di karya seni Siria dan Mesir. Masa Byzantine tengah ditandai melalui pergolakan Ikonoklasme selama 150 tahun (penolakan akan keabsahan penggunaan Ikon). Menangnya kelompok pecinta Ikon, kemudian menghasilkan pembaharuan semangat masyarakat pada seni rupa Gerejawi. Pada periode ini muncul kecenderungan untuk merepresentasikan dimensi rohani yang melampaui pandangan mata (direpresentasikan dalam metode gambar klasik yang cenderung tiga dimensional) Peninggalan Byzantine Tengah dapat disaksikan pada hari ini pada seni monumental di biara-biara seperti di Biara Daphni dekat Athena, dan biara Hosios Loukas. Pada Masa ini gambar-gambar yang bersifat naratif dimunculkan sebagai Ikon dengan dan dikenal sebagai Menologion, yaitu ikon-ikon penanda pesta-pesta Gerejawi. Periode Byzantine Akhir ditandai oleh direbutnya kembali Konstantinopel pada tahun 1261 dari Pendudukan Tentara Salib. Periode ini menandai awal dari masa keemasan seni rupa Byzantine yang terakhir. Periode ini ditandai dengan gaya monumentalisme gambar-gambar yang besar namun lebih sederhana yang mengenang kejayaan abad 11, muncul pula ikon berjenis Hagiografis (narasi kehidupan orang suci dalam bentuk panel-panel kecil pada keempat sisi ikon seorang suci), perkembangan aliran-aliran ikonografi lokal seperti di Serbia dan Bulgaria, dan setelah jatuhnya Konstantinopel ke tangan Ottoman, muncul pusat-pusat ikonografi baru seperti di Kreta dan Russia.

Dalam Gereja Orthodox, ada sebuah pesta Gerejawi yang dikenal dengan nama Pesta Transfigurasi/metamorphosis. Pesta ini merayakan pengubahmuliaan Yesus Kristus di atas Gunung. Dalam ikonografi, pesta ini ditandai dengan Ikon Menologion Transfigurasi. (Nes, 2007, hal. 13) menjelaskan bahwa narasi Alkitab yang digambarkan pada ikon ini dibagi menjadi menjadi tiga bagian yaitu anabasis/pendakian,

Teophany/Penampakan Illahi, dan katabasis/penurunan. Dalam karya tulis ini, penulis menggunakan replika Ikon 
Transfigurasi yang berasal dari tahun 1547 dan digunakan dalam peribadatan di Paroikia St. Dionysios dari Zakynthos, Kricak Kidul, Yogyakarta.

\section{B. Pembahasan}

Secara tradisional, Ikon Byzantine dilukis dengan metode yang dipertahankan secara turun temurun. Material yang digunakan adalah kayu yang dilapisi dengan kanvas yang telah direndam dalam lem khusus. Kayu sebelumnya diproses sedemikian rupa agar tidak berubah bentuknya sementara kanvas yang dipilih dari kain yang terbaik. Pewarna yang digunakan adalah dari bebatuan alamiah yang digerus terus menerus menjadi bubuk

warna dan dicampur dengan kuning telur sebagai perekat antara pigmen dengan kanvas. Media lukis ini disebut sebagai egg tempera. Latar belakang ikon menggunakan warna emas sebagai lambang dari kemuliaan. Ikon memiliki gaya gambar yang cenderung simbolik dan tereduksi, terdapat kekhasan dalam bentuk dan figur. Ikon yang penulis gunakan adalah ikon replika yang dicetak diatas kertas art paper berukuran 27 x $40 \mathrm{~cm}$ yang dibingkai dengan kayu.

Ikon Transfigurasi ini memiliki tiga bagian dalam satu ikon yaitu ascent/anabasis (pendakian), Transfigurasi/Metamorphosis (pengubahmuliaan), dan descent/katabasis (penurunan).

Narasi

Transfigurasi/Metamorphosis bersumber dari berbagai tulisan namun utamanya tercatat dalam injil sinoptik (Matius, Markus Lukas) dengan narasi yang kuran lebih sama yaitu, Kristus mengajak tiga muridnya yaitu Petrus, Yakobus dan Yohanes ke atas gunung, disana Ia terubah-muliakan dalam terang yang membutakan dan tampak bercakap-cakap dengan dua orang nabi dari perjanjian lama, dan pada akhirnya mereka turun dari sana dimana Kristus meminta murid-muridnya merahasiakan hal tersebut hingga kebangkitanNya dari antara orang mati.

Tiga struktur Ikon ini penulis hubungkan dengan struktur satu lingkaran pesta dalam lingkaran liturgis Gereja
Orthodox yaitu pra-pesta (5 Agustus), Pesta (Metamorphosis) (6 Agustus), dan Pasca Pesta (Apodosis) (13 Agustus). Pesta Transfigurasi dirayakan tiap tahunnya pada tanggal 6 Agustus dan juga ikut dirayakan pemberkatan buah sulung pada hari tersebut.
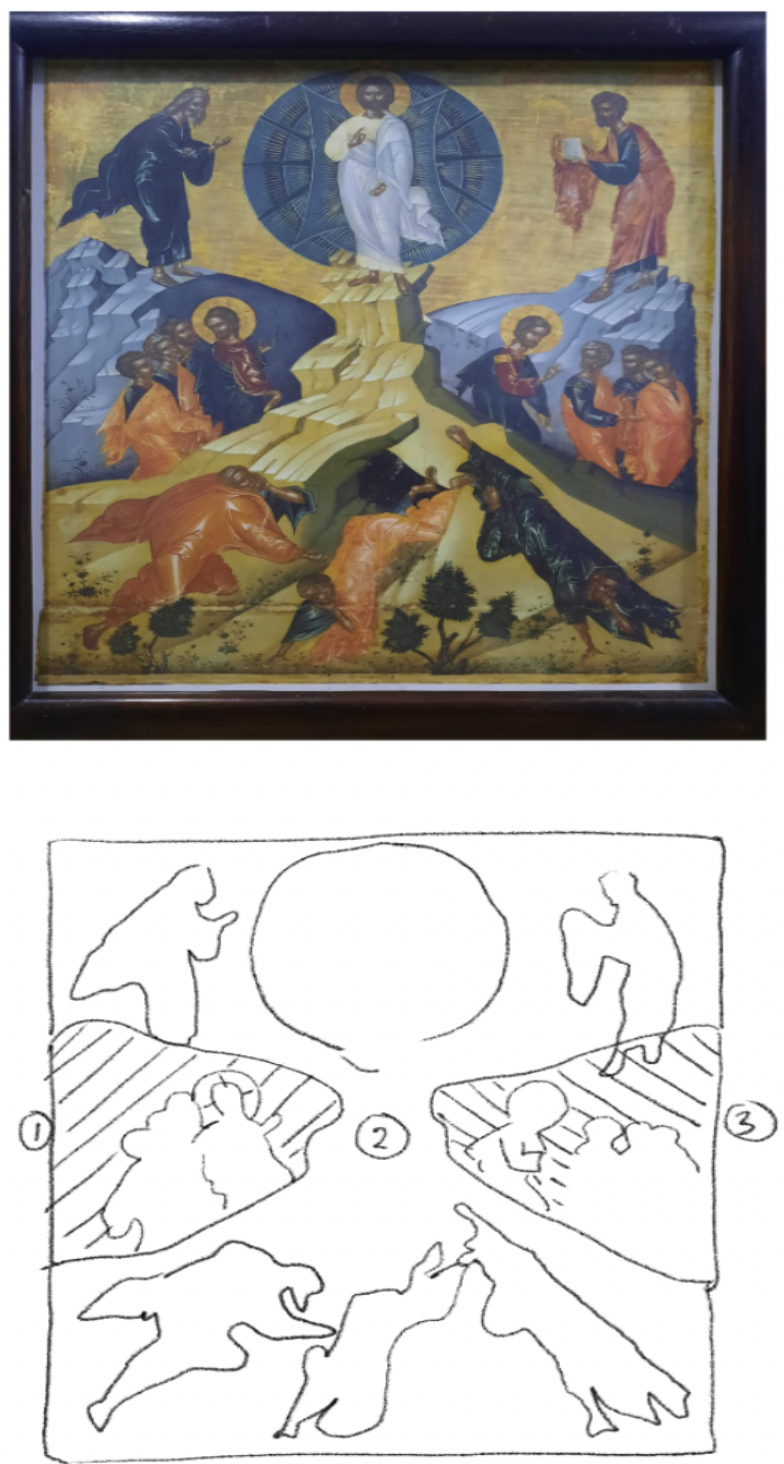

Komposisi ikon Transfigurasi dari periode Byzantine Akhir memiliki skema yang cenderung simetris dan memiliki gaya visual yang khas. Ikon dapat kita lihat terbagi kedalam tiga bagian yaitu anabasis di sisi kiri (1), Theophany disisi tengah dan memakan ruang yang paling banyak (2) dan katabasis (3) di sisi kanan. Ikon Transfigurasi tersebut dapat kita lihat tidak menggambarkan figur-figur yang statis namun menunjukkan adanya aksi, gerak 
serta drama. Narasi dalam ikon ini termasuk dalam narasi polyscenic yang menggambarkan sebuah urutan kejadian yang ditarik dalam sebuah geografis yang terpanjangkan dan terdefinisi dengan baik, meskipun tidak selalu dalam urutan yang kronologis (Jain dan Daljeet dalam Woodside, 2010).

\section{a. Anabasis}

Bagian anabasis dalam Ikon ini mengilustrasikan tiga kejadian yang sama dalam injil sinoptik.
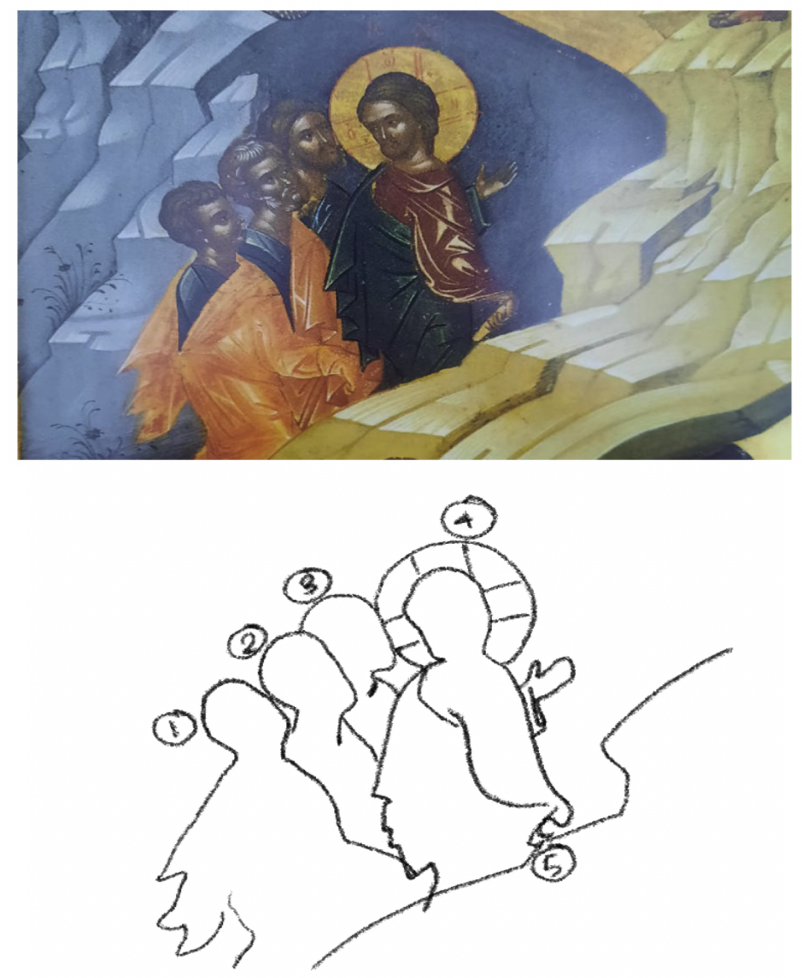

Dalam Matius 17:1 dan Markus 9:2 tertulis “...Yesus membawa Petrus, Yakobus dan Yohanes saudaranya, dan bersamasama dengan mereka Ia naik ke sebuah gunung yang tinggi." Dalam Lukas 9:28 tertulis ..."Kira-kira delapan hari sesudah segala pengajaran itu, Yesus membawa Petrus, Yohanes dan Yakobus, lalu naik ke atas gunung untuk berdoa. Narasi anabasis ini digambarkan dalam ikon dimana terdapat tiga figur murid mengikuti Kristus dari belakang beranjak naik ke sebuah gunung. Figur 1 adalah Yohanes yang digambarkan sebagai figur yang paling muda, figur 2 adalah Petrus, figur 3 adalah Yakobus dan figur 4 adalah Kristus yang memegang sebuah gulungan (5).
Figur Yohanes digambarkan sebagai yang paling muda dalam banyak ikon lainnya. Hal ini sesuai dengan narasi sejarah dimana Yohanes adalah Rasul yang wafat paling terakhir di pulau Patmos pada akhir abad pertama. Dalam Ikonografi Byzantine, ia selalu digambarkan tidak berjanggut ketika digambarkan bersama dengan Kristus. Rasul Petrus digambarkan dengan janggut putih dan Yakobus digambarkan mirip dengan Kristus untuk menunjukkan adanya hubungan darah (sepupu) antara keduanya. Jubah Yohanes dan Petrus dilapisi dengan jubah luar berwarna oranye, warna ini tergolong unik dalam ikonografi Byzantine, karena jarang digunakan. Kita dapat memahaminya sebagai sebuah artistic device yang dimanfaatkan oleh pelukis untuk menonjolkan pengelompokan keempat figur dialam sebuah panel yang dikonstruksikan sebagai sebuah latar belakang berupa gunung yang berwarna biru. Kristus digambarkan dengan halo (lingkaran emas) dengan tiga garis dimana terdapat huruf dalam bahasa Yunani yang bertuliskan Ho On dan Kristogram (tulisan IC XC). Kata Ho On berarti "Aku adalah Aku, yang Ada". Kata-kata ini juga muncul dalam penampakan Illahi yang dialami oleh Musa dalam Keluaran 3:14 "Lagi firman-Nya: "Beginilah kaukatakan kepada orang Israel itu: AKULAH AKU telah mengutus aku kepadamu." Sementara Kristogram IC XC merupakan penyederhanaan dari kata Iesus Khristos (Yesus Kristus dalam bahasa Yunani). Kristus digambarkan dalam mengenakan jubah dalam berwarna berwarna merah dan jubah luarnya berwarna biru. Makna dari hal ini adalah penggambaran dwi-kodrat Kristus yang adalah Allah dan Manusia sekaligus. Ia memegang sebuah gulungan tertutup yang merupakan perlambang sebuah rahasia yang belum terbuka. Hal ini kemudian akan dinyatakan dalam narasi kedua yaitu Theophany dan pada narasi ketiga, gulungan tersebut sudah tidak ada lagi.

Dalam teks liturgi pra-pesta (5 Agustus), dapat dilihat korelasi antara narasi ikon menologion ini dengan teks stikhera sembahyang senja yang 
mendahului pesta Transfigurasi. Dalam teks sembahyang senja tertulis,

"Marilah kita bersukacita, mendaki dari bumi kepada perenungan tertinggi dari kebajikan, marilah kita mengubahkan hari ini menjadi hari yang lebih baik dan mengarahkan pikiran kita pada hal-hal surgawi, dengan diperbaharukan menurut rupa Kristus, karena dalam belaskasihanNya Sang Juru selamat jiwa kita telah mengubah muliakan manusia yang telah rusak dan membuatnya bersinar dengan terang diatas Gununt Tabor" (Ware \& Mary, 1984, hal. 472).

\section{b. Theophany/Transfigurasi/Metam orphosis}

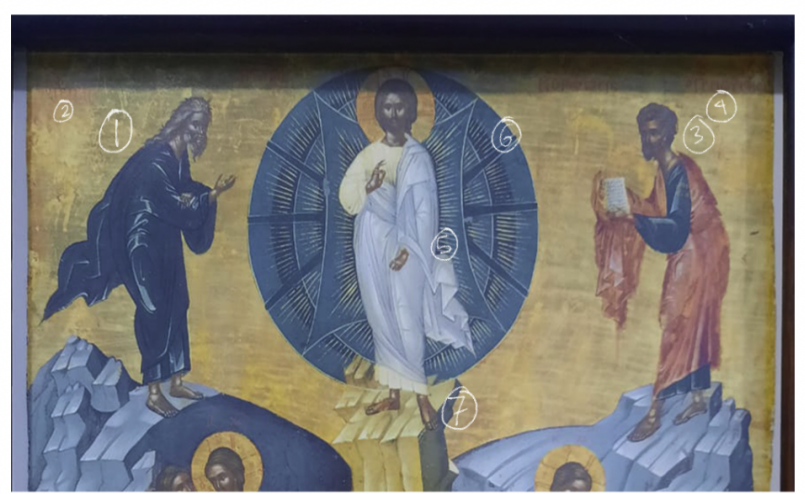

Pada bagian Theophany, sumber dari Alkitab diambil dari tiga injil sinoptik yaitu Matius 17:2-4, Markus 9-2b-6 dan Lukas 9:29-34. Ada 2 figur yang mengapit Kristus yang digambarkan telah terubahmuliakan. Dari teks Berbahasa Yunani (2) kita dapat mengidentifikasikan bahwa figur (1) adalah Elia yang digambarkan berambut putih dan panjang dengan jubah berwarna biru yang berkibar. Elia adalah nabi di Perjanjan Lama yang dipindahkan dengan Kereta Berapi ketas langit dalam angin badai (2 Raja-Raja 2). Sementara di sisi kanan dari teks bahas Yunani (4) kita dapat mengidentifikasikan bahwa figur (3) adalah Nabi Musa. Ia berjubah dalam biru dengan jubuah luar Merah dan memegang gulungan. Kedua figur Musa dan Elia merepresentasikan Nabi dan Hukum Taurat, keduanya disaksikan dalam Perjanjian Lama mengalami Allah dimana Musa mengalamiNya diatas Gunung Sinai dan api daitas Gunung Karmel, serta Elia mengalaminya dengan terangkat keatas langit (Nes, 2007, hal. 68). Keduanya memandang Kristus yang berubah rupa dimana jubahnya menjadi putih dalam dua shade (putih kekuningan dan putih kebiruan), menggambarkan kemurnian kedua kodratnya (5) dan menyinarkan terang yang menyilaukan (6) yaitu Terang yang Tak Tercipta sembari berdiri diatas puncak gunung (7) sebagai pre-figurasi atau pra-penggambaran penyaliban. Musa dan Elia digambarkan bertatap-tatapan dengan tenang melihat terang yang membutakan sementara para murid bereaksi sebaliknya.

Terang yang Tak Tercipta digambarkan dengan warna biru, yang dalam makna warna menurut budaya Byzantine merupakan warna kemuliaan dan warna langit. Untuk mendapatkan warna ini, diperlukan bubuk dari lapis lazuli yang adalah bebatuan yang mahal dan berharga. Sementara itu garis-garis sinar dalam terang tersebut digambarkan dengan emas yang diletakan dengan teknik gilding, Kertaskertas emas ditempelkan secara sedemikian rupa dalam bentuk garis-garis dan memancar ke segala arah menggambarkan terang Kristus memancar ke seluruh alam. Terang ini juga muncul dengan bentuk yang mirip dengan terang yang Kristus tampakkan dalam ikon Kebangkitan/Paskah.

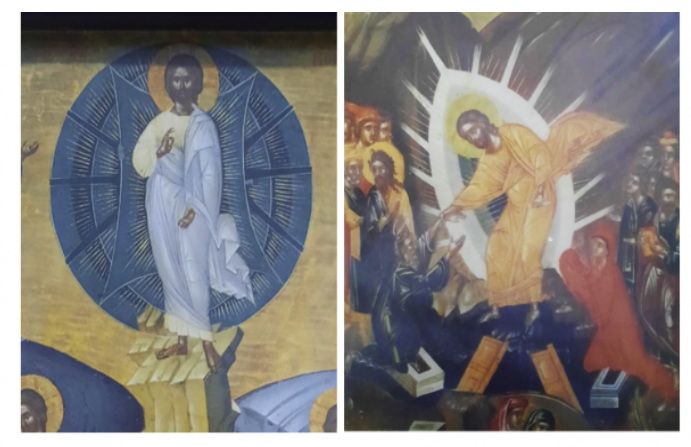

Penggambaran terang Illahi dalam ikon Transfigurasi (kiri) dan ikon Kebangkitan (kanan)

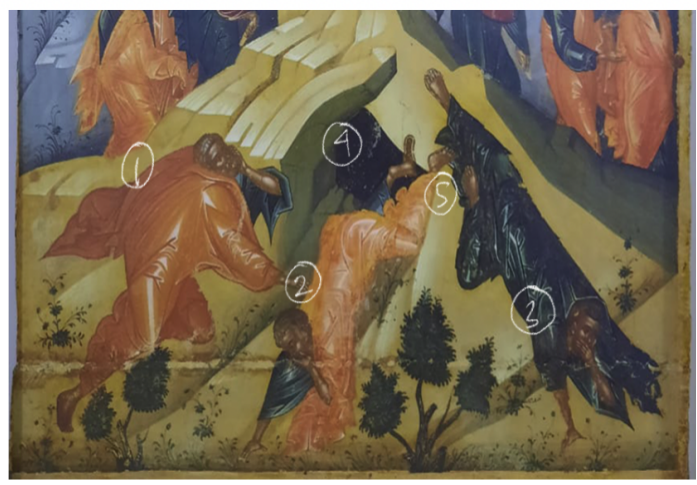


Para murid digambarkan terjungkal dan menjauh dari Figur Kristus yang terang benderang dan terlihat ketakutan. Mereka digambarkan seperti tiga arah yang memancar ke tiga arah yang berbeda. Dalam ikonografi lain, terang Kristus digambarkan dengan tiga panah cahaya namun dalam ikon ini, tiga panah tampaknya disubstitusikan dengan tiga arah yang berbeda dari gerak para murid/rasul. Figur Petrus (1) digambarkan mencoba mengintip kemuliaan Kristus sementara Yohanes (2) dan Yakobus (3) ketakutan hingga terjungkal ke tanah. Kekacauan manusia dalam ketakmampuannya menikmati kemuliaan Allah digambarkan dengan terjungkalnya para Murid dan lepasnya alas kaki mereka (5). Hal ini mengingatkan pada perintah Allah kepada Musa untuk melepaskan alas kakinya karena sedang berdiri di tanah yang suci. Kekacauan ini juga digambarkan berdekatan dengan gambar gua yang gelap (4) yang menggambarkan kematian. Dalam ikon penyaliban, transposisi antara ikon Transfigurasi ini dapat memberikan arti yang lebih lengkap sebagaimana Peristiwa Transfigurasi merupakan permulaan sebelum Kristus masuk Ke Yerusalem untuk memulai perjalanan deritaNya yang terkulminasi pada Penyaliban. Hal ini juga disaksikan dalam berbicara tentang tujuan kepergian-Nya yang akan digenapi-Nya di Yerusalem.

Selain Kesaksian dari Injil Sinoptik, Rasul Yohanes sebagai saksi mata langsung dari kejadian tersebut juga menuliskan pengalaman mereka pada Injil yang Ia susun (Firman itu telah menjadi manusia, dan diam di antara kita, dan kita telah melihat kemuliaan-Nya, yaitu kemuliaan yang diberikan kepada-Nya sebagai Anak Tunggal Bapa, penuh kasih karunia dan kebenaran. (Yohanes 1:14). Petrus mengenang kembali pengalamannya yang ia tulis dalam 1 Petrus 1:17 (..bagaimana Ia menerima kehormatan dan kemuliaan dari Allah Bapa, ketika datang kepada-Nya suara dari Yang Mahamulia, yang mengatakan: "Inilah Anak yang Kukasihi, kepada-Nyalah Aku berkenan." Suara itu kami dengar datang dari sorga, ketika kami bersama-sama dengan Dia di atas gunung yang kudus.")



Dalam Teks Liturgis, fase Teophany direpresentasikan dalam banyak sekali teks-teks Sembahyang Senja (Vesper), Sembahyang Fajar (Matins), dan Liturgi Illahi. Ada sebuah teks yang digunakan dalam peribadatan dan dikenal sebagai Apolytikion. Apolytikion adalah sebuah jenis troparion yaitu sebuah jenis kidungan dalam tradisi Byzantine yang berasal dari daerah Siria-Palestina. Apolytikion didaraskan tiga kali pada akhir Vesper bila Pesta yang dirayakan adalah Pesta Besar (Conomos dalam McGuckin, 2010, hal. 862 dan 632). Teks tersebut berbunyi "Engkau Telah dimuliakan diatas gunung Ya Kristus Allah, menunjukkan kemuliaanMu kepada muridMu, sejauh mereka mampu menerimanya. Melalui doa-doa Bunda Allah, buatlah terang abadiMu juga bersinar kepada kami orang Berdosa, Ya Sang Pemberi Terang, Kemuliaan BagiMu." (Ware \& Mary, 1984, hal. 477-478). Dalam lingkar kalender pesta Transfigurasi, kidungan ini akan terus dinyanyikan dalam setiap ibadah.

\section{c. Katabasis}
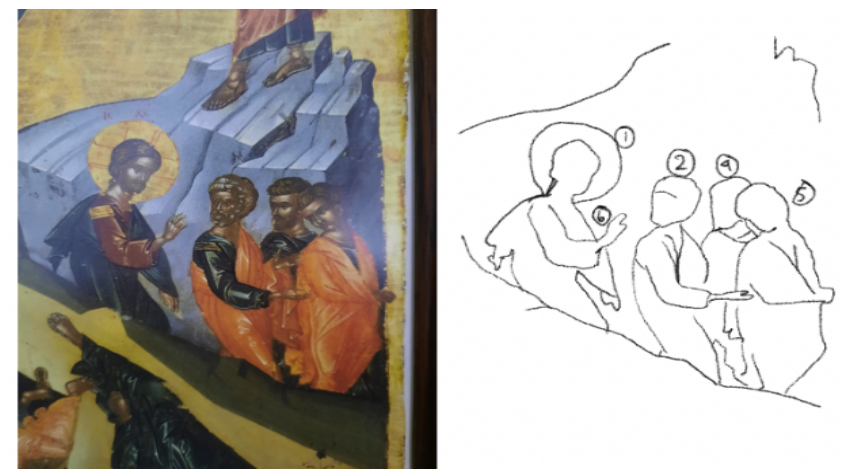

Dalam Ikon Transfigurasi, bagian Anabasis menunjukkan ke-empat figur 
turun dari gunung dimana para murid (2-45) berdiri didepan seakan-akan mereka hendak lari ketakutan menghindari Kristus. Figur Kristus (1) kembali digambarkan dengan jubah Merah-Biru dan menunjukkan figur memberkati (6). Para murid memunggungi Kristus menggambarkan ketakutan namun mereka tetap menengok kearah Dia menggambarkan ada iman dalam diri mereka. Warna jubah mereka tetap tidak berubah.

Dalam Teks liturgis, peristiwa Katabasis direpresentasikan pada hari Apodosis (Pasca-Pesta) yaitu pada hari terakhir lingkaran pesta Transfigurasi dan diperingati pada tanggal tanggal 13 Agustus. Dalam ibadat gerejawi yang dilakukan pada hari Apodosis, teks-teks liturgis pesta untuk sekali lagi dinyanyikan sebelum lingkaran pesta meninggalkan lingkar Pesta Transfigurasi dan bergerak kepada lingkaran selanjutnya.

\section{Kesimpulan}

Dr. Jevtic (2014) dalam kuliah umumnya menjelaskan bahwa narasi adalah sebuah fenomena universal yang memiliki sebab-akibat. Narasi adalah sebuah hal yang sangat mendasar sebagai salah satu bentuk pemikiran manusia yang memampukan seseorang untuk merepresentasikan, menegakkan, dan mengkomunikasikan pengetahuan tentang sebuah realita yang dinikmati bersama, atau menghantarkan suatu hal agar dapat menjadi realitas bersama melalui narasi yang dikonstruksikan suatu budaya/masyarakat. Ikonografi Byzantine yang berjenis Menologion mencoba untuk menarasikan sebuah kejadian yang panjang dalam satu ilustrasi yang bersifat polyscenic. Sebuah ikon menologion memiliki tiga bagian yaitu Intro-Puncak-Epilog, dimana dalam ikon Pesta Transfigurasi dikenal dengan tiga bagian tersebut dikenal sebagai Anabasis Theophany/Metamorphosis - Katabasis. Ikon tidak hanya dimanfaatkan sebagai dekorasi Gereja, yaitu sebagai monumental painting. Ikon juga tidak hanya berfungsi sebagai literary device, namun juga berfungsi sebagai penanda waktu dan ruang dan berhubungan erat dengan pemahaman teologis yang diekspresikan bersama-sama dalam peribadatan melalui nyanyian dan teks-teks ibadah. Ikon Transfigurasi menggambarkan pula peristiwa yang lampau (Para Nabi), Peristiwa yang sedang Terjadi (transfigurasi) dan peristiwa masa depan/Eschaton yaitu peristiwa Penyaliban. Narasi ini berguna untuk mengingatkan dan menghantarkan realitas rohani yang tak nampak mata dan telah terjadi di masa lalu.

\section{Kepustakaan}

Alkitab. (2002). Jakarta: Lembaga Alkitab Indonesia

Marianto, M. D. (2019). Seni dan Daya Hidup Dalam Perspektif Quantum. Scritto books \& BP ISI Yogyakarta.

McGuckin, J. A. (2010). The Orthodox Church: An introduction to its history, doctrine, and spiritual culture. John Wiley $\&$ Sons.

Nes, S. (2007). The Uncreated Light: an iconographical study of the transfiguration in the Eastern Church. Wm. B. Eerdmans Publishing.

Nes, Solrunn. 2005, The mystical language of Icons. Michigan/Cambridge. William B. Eerdmans Publishing Company.

Ware, K., \& Mary, M. (1984). The Festal Menaion. Faber and Faber.

Woodside, A. G. (2010). Case study research: Theory, methods and practice. Emerald Group Publishing.

Webtografi

Ivana Jevtic. 2014. Narration or Visual Storytelling in Late Byzantine Painting (1261 https://www.youtube.com/watch?v=X RmPiTBhv40 diakses pada 18 Mei 2021 